DOI 10.37882/2223-2974.2020.12.25

\title{
МЕХАНИЗМЫ РАЗВИТИЯ ОТРАСЛЕЙ ДОБЫВАЮЩЕЙ ПРОМЫШЛЕННОСТИ В РЕСПУБЛИКЕ КАЗАХСТАН С УЧЕТОМ МЕЖДУНАРОДНОГО ОПЫТА
}

\section{MECHANISMS FOR THE DEVELOPMENT OF THE EXTRACTIVE INDUSTRY IN THE REGION OF KAZAKHSTAN, TAKING INTO ACCOUNT INTERNATIONAL EXPERIENCE \\ K. Nevmatulina \\ O. Zhidkoblinova \\ A. Mussatayeva Ye. Stavbunik}

Summary:The extractive industry is one of the main sectors of the economy of the Republic of Kazakhstan. A distinctive feature of the industry is both the variety of extracted minerals and a large number of enterprises working in the field of exploration and exploitation of deposits. One of the prerequisites for achieving sustainable development of the industry is the existence of adequate laws, regulations and standards or mining legislation, as well as a system of institutional structures to ensure the implementation of these laws.

Keywords: extractive industry, gross domestic product, reforms, tax.

\author{
Невматулина Карина Анваровна \\ PhD, Дочент, Карагандинский экономический \\ университет Казпотребсоюза, Республика Казахстан \\ carisha_07@mail.ru \\ Жидкоблинова Олеся Владимировна \\ $\mathrm{PhD}$, Дочент, Карагандинский экономический \\ университет Казпотребсоюза, Республика Казахстан \\ olesya.zhidkoblinova@mail.ru \\ мусатаева Асемгуль Амангазиевна \\ PhD, Карагандинский экономический университет \\ Казпотребсоюза, Республика Казахстан \\ m_assem1984kz@mail.ru \\ Ставбуник Елена Анатольевна \\ PhD, Старший преподаватель, Карагандинский \\ экономический университет Казпотребсоюза, \\ Республика Казахстан \\ sea826@yandex.kz
}

Аннотация: Добывающая промышленность представляет собой одну из основных отраслей экономики Республики Казахстан. Отличительной особенностью отрасли является как разнообразие добываемых полезных ископаемых, так и большое количество предприятий, работающих в сфере разведки и эксплуатации месторождений. Одним из обязательных условий достижения устойчивого развития отрасли является наличие адекватных законов, нормативных актов и стандартов или горного законодательства, а также системы институциональных структур, обеспечивающих выполнение этих законов.

Ключевые слова: добывающая промышленность, внутренний валовый продукт, реформы, налоги.

Тенденция к снижению цен на сырьевые товары, наблюдавшаяся с 2012 года, отрицательно влияла на экономику страны: так, к началу 2016 года, то есть за пятилетний период, цены на металл упали почти на 60\%. В 2015 и 2016 годах реальный рост ВВП Казахстана снизился до 1,2 и 1\% соответственно, чего не происходило с 1990-х годов. И, хотя в 2019 году темпы роста снова увеличились до 4,5\%, для восстановления экономики нужен толчок, который помог бы Казахстану снова встать на путь быстрого приближения к наиболее развитым государствам мира.

Казахстан занимает примерно 50-ое место в списке стран по номинальному значению валового внутреннего продукта (ВВП). В 2018 г. ВВП РК составил 61,8 трлн. тенге (3,4 млн тенге на душу населения, или 9812,5 долларов США). За 9 месяцев 2019 г. ВВП РК составил 44,3 трлн тенге. Оценка ВВП РК за полный 2019 год составляет 67,7 трлн. тенге. 
В связи с сырьевой направленностью и экспортной ориентированностью экономики Казахстана ее развитие тесно связано с ситуацией на рынке сырьевых товаров, прежде всего нефти и металлов. С 2000 по 2011 годы ВВП РК показывал стремительный реальный рост на двузначном уровне с кратковременными корректировками в 2008-2009 г. в связи с влиянием мирового финансового кризиса. С 2012 по 2014 годы темпы роста страны стабилизировались на уровне 4-6\%. Подобная динамика темпов роста объясняется существенным укрупнением экономики страны на фоне высоких цен на нефть и металлы. В 2015-2016 г. наблюдалось падение роста ВВП до 1,2 и 1,1\% соответственно, что пошло следствием кризиса обрушившихся цен на нефть. При этом с 2017 года наблюдается восстановление показателей экономического роста
Казахстана - чуть выше 4\% (Рисунок 1).

Как известно, горнодобывающая отрасль Казахстана обеспечивает более четверти ВВП страны. Она представлена в основном несколькими крупными предприятиями, при этом часть акций наиболее значимых производителей нетопливного минерального сырья принадлежит государству (Рисунок 2).

В настоящее время в структуре ВВП Казахстана промышленное производство составляет $44 \%$.

Объемы промышленного производства в денежном выражении составили 27,2 трлн. тенге. В структуре промышленного производства лидирующие позиции занимают горнодобывающая и обрабатывающая промыш-

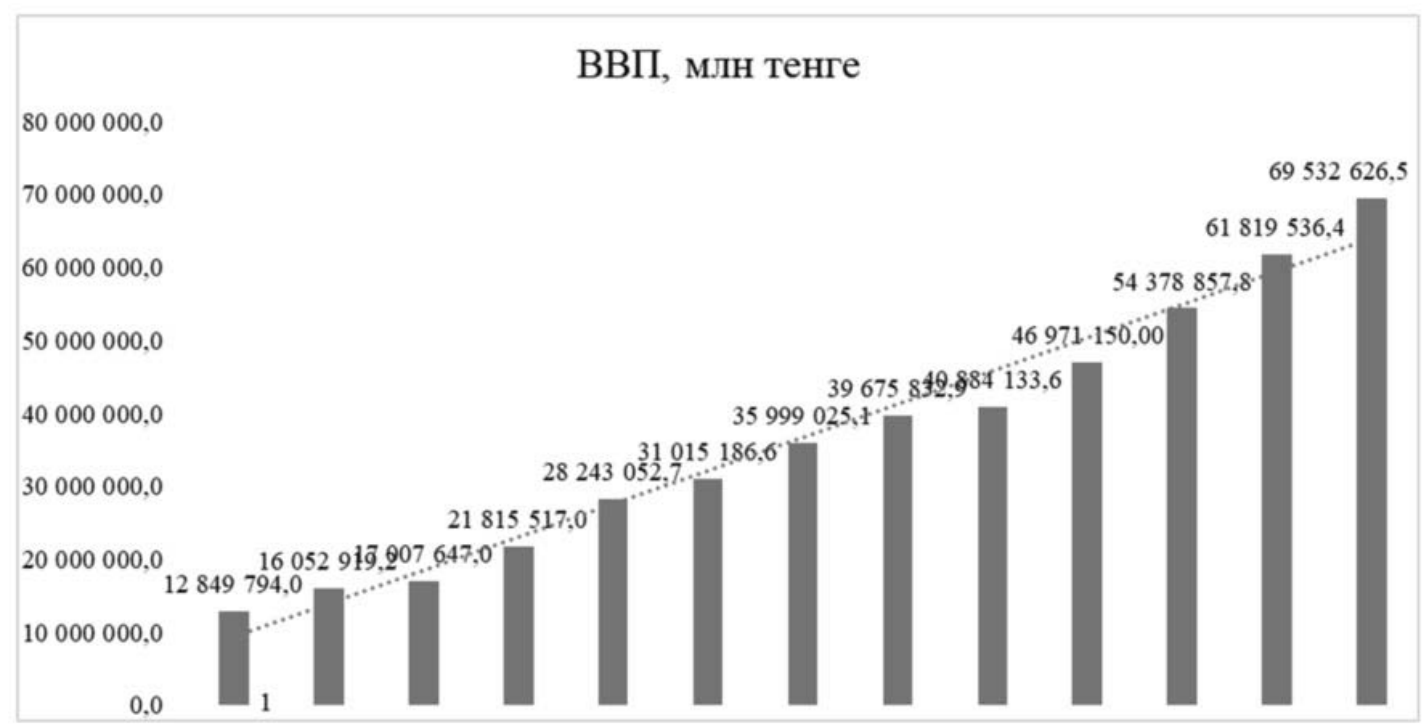

Рис. 1. Динамика объемов ВВП В Республике Казахстан

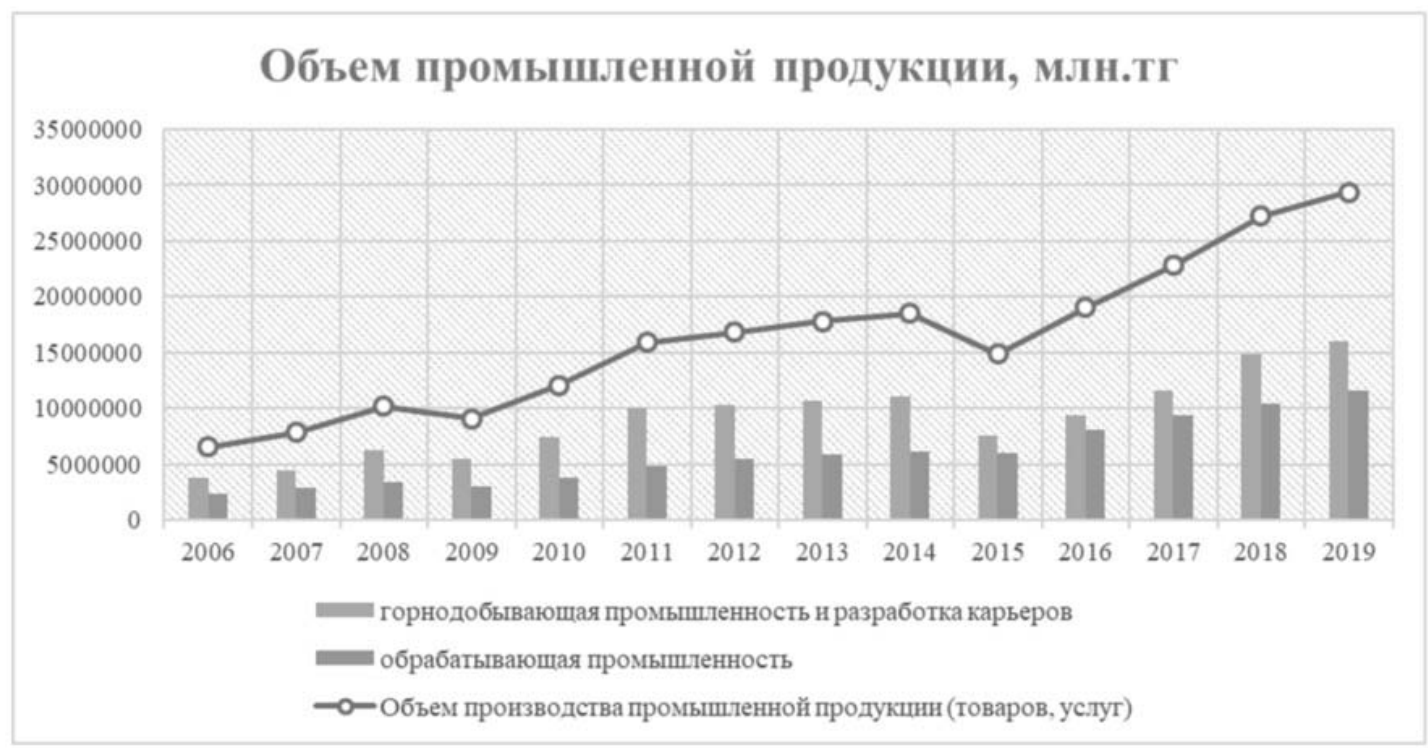

Рис. 2. Динамика объемов производства промышленной продукции 
ленности - 54\% и 38\% соответственно [1].

Рискованные геологоразведочные работы на ранних этапах в основном выполняют небольшие юниорские компании. Однако, масштаб геологоразведочных работ в Казахстане за последние 30 лет был ограниченным, а отрасль твердых полезных ископаемых добилась значительно меньших успехов в деле привлечения иностранных инвестиций, нежели углеводородная. Недавние реформы отчасти направлены на сокращение этого разрыва и создание заметно более привлекательных условий для инвестиций в новые проекты по разведке и добыче. Правительство Республики Казахстан приняло меры по приведению горного законодательства в соответствие с конкурентоспособными международными моделями и формированием среды, благоприятствующей инвестициям, в том числе со стороны зарубежных юниорских компаний.

С января 2015 года ОЭСР поддерживала начинания в данной сфере в рамках проекта «Повышение конкурентоспособности горной промышленности в Казахстане», в ходе которого был выполнен широкий спектр работ, включая экспертные анализы и консультации с властями и частным сектором. По итогам всех мероприятий удалось сделать выводы, которые помогли согласовать казахстанское законодательство с принципами, принятыми в горных юрисдикциях в странах-членах ОЭСР [2]. В декабре 2017 года был принят новый Кодекс Республики Казахстан «О недрах и недропользовании», который вступил в силу в июле 2018 года. Отражая результаты проделанной работы, и, представляя важный шаг вперед во многих аспектах, при условии грамотной реализации он способен укрепить доверие инвесторов [3].

Данный кодекс вобрал в себя передовой опыт нормативно-правового регулирования деятельности по добыче твердых полезных ископаемых. Помимо прочих положительных нововведений, в нем содержатся положения, упрощающие порядок выдачи разрешений, что свидетельствует о готовности Казахстана следовать примеру Западной Австралии. Так, в новом кодексе вводится порядок предоставления права недропользования по принципу «первой заявки». Такая мера является давно ожидаемой со стороны недропользователей, которые желают осуществлять геологоразведочные работы. Помимо этого, владельцам лицензии на разведку гарантируется последующее получение лицензии на разработку соответствующего участка недр. Порядок ответа на поступившие заявки также регламентируется. Несмотря на сохранение преимущественного права государства (по аналогии с Чили или Британской Колумбией в Канаде), ожидается, что эти общие положения встретят одобрение у многих представителей отрасли.

Несмотря на заметный прогресс, еще предстоит ре- шить ряд серьезных проблем, особенно в сфере налогообложения и надзора.

Что касается налогообложения предприятий горной промышленности, чему в Налоговом кодексе посвящен отдельный раздел, учет в налоговой базе запасов полезных ископаемых вместо использования более привычного механизма налогообложения выручки с продаж/ прибыли будет по-прежнему волновать недропользователей, так как налоговое обязательство может возникнуть независимо от рентабельности запасов в конкретный момент времени.

В новом кодексе сохраняется более строгий контроль за недропользованием по сравнению с ситуацией в странах - участницах ОЭСР. Так, на этапе разведки и добычи запрещается вносить любые коррективы в план производства горных работ, в том числе в используемые недропользователями методы и способы, не согласовав их с властями. Это ограничивает способность недропользователей адекватно реагировать на изменение рыночной конъюнктуры. К тому же, в новом кодексе отсутствуют положения, устанавливающие контроль за деятельностью недропользователей в зависимости от присущих ей рисков.

В целом, безусловно, реформы соответствуют рекомендациям, предложенным в рамках проекта, как, например, в случае с изменением порядка выдачи разрешений, что должно помочь Казахстану увеличить приток капиталовложений в геологоразведочную деятельность. Тем не менее, ряд ключевых аспектов, в том числе порядок осуществления надзора и систему налогообложения в соответствующей сфере, еще предстоит доработать. Если эти вопросы останутся нерешенными, существует вероятность того, что эффект от многочисленных положительных преобразований будет ограниченным. Дальнейшая работа в этом направлении наряду с проведением соответствующих налоговых и экологических реформ должна повысить привлекательность горной промышленности для прямых иностранных инвестиций и ее конкурентоспособность в целом.

Результат реформ в горной отрасли Казахстана всецело зависит от эффективности практической реализации. Наилучшим способом заручиться доверием инвесторов станет справедливый, последовательный и прозрачный характер применения новых правил и процедур. Регулярный мониторинг мероприятий по реализации и внесение коррективов на основе фактических данных тоже будут способствовать успеху.

В целях создания рамочной политики, способствующей наращиванию устойчивости горной промышленности Казахстана и укреплению доверия инвесторов, уже принят ряд важных мер. Как уже отмечалось ранее, всту- 
пление в силу нового кодекса «О недрах и недропользовании» уже помогло приблизить состояние нормативноправовой среды Казахстана к стандартам, существующим во многих странах ОЭСР, заинтересованных в развитии горной промышленности. В частности, этому должна способствовать рационализация процесса лицензирования, упрощение доступа к геологической информации и увеличение прозрачности отрасли. Помимо этого, в новом законодательстве уделено немало внимания вопросам экологической экспертизы и оценки, что должно сыграть свою роль в управлении рисками, связанными с воздействием недропользования на окружающую среду. Наряду с положительными изменениями, которые привнес новый кодекс «О недрах и недропользовании», горной промышленности коснется и ряд нововведений в налоговой сфере, предусмотренных новым Налоговым кодексом, который вступил в силу с января 2018 года [4].

В то же время, в целях сокращения наиболее значительных разрывов между опытом стран ОЭСР и новой базой в Казахстане необходимо рассмотреть дальнейшие меры в определенных областях экономической политики, направленные на повышение привлекательности горной промышленности для прямых иностранных инвесторов и на рост ее конкурентоспособности в целом [5]:

1. создание реестра горного производства. Электронный реестр действующих, закрытых и заброшенных объектов горного производства позволил бы держать под контролем осуществление горных работ во всей стране;

2. укрепление механизмов обеспечения исполнения обязательств по ликвидации последствий недропользования. Целесообразно разработать надзорный механизм, который позволил бы следить за тем, чтобы сумма финансовой гарантии или залога, предоставленная недропользователем, полностью покрывала стоимость ликвидации, а также меры по урегулированию вопросов финансирования в связи со старыми шахтами;

3. повышение доступности и качества информации. В целях упрощения толкования положений кодекса «О недрах и недропользовании» можно добавить в него перечень терминов и определений различных видов полезных ископаемых. Кроме того, перевод Кодекса на английский язык позволил бы расширить круг потенциальных инвесторов;

4. дальнейшее сближение налогообложения недропользователей с системами, принятыми в странах ОЭСР:

- налоговые реформы 2018 года должны способствовать повышению привлекательности горной промышленности Казахстана. Однако решающую роль в эффективной реализации положений нового законодательства и достижении положительных результатов сыграет компетентность налоговых органов, которым придется контролировать новые механизмы и осуществлять проверку предприятий;

- по мере возможности следует избегать новых серьезных изменений в налогообложении недропользования в ближайшей перспективе, пока эффект новой системы не будет тщательно проанализирован, например, по происшествии трех лет;

- в результате изменений необходимо будет отслеживать состояние бюджета, чтобы проверить, не окажется ли потеря доходов от горной промышленности больше ожидаемой. В случае недопоступлений следует провести тщательный диагностический анализ, и лишь потом приступать к дальнейшему пересмотру налогового законодательства. Любые существенные перемены в налоговой политике грозят ослабить эффект изменения налогового режима как таковой, поскольку инвесторы усомнятся в стабильности налоговых условий на будущее;

- представляется целесообразным и далее постепенно продвигаться к внедрению международных стандартов в налогообложении недропользователей. В частности, рекомендуется переход Казахстана к системе обложения налогом исходя из объемов реализации полезных ископаемых, применяемой в большинстве стран. Отметим, что такое изменение может увеличить риск трансфертного ценообразования, а потому можно рассмотреть возможность поэтапного перехода, то есть сначала внедрить новшество лишь в отношении полезных ископаемых, сбываемых на прозрачных международных рынках, чтобы дать налоговым органам время освоить новые правила;

5. укрепление системы представления отчетности и введение подхода к контролю, основанного на оценке рисков, в отрасли:

- введение подхода, основанного на оценке рисков, к контролю за изменениями планов горных работ обеспечило бы недропользователям определенную свободу действий, необходимую для эффективного реагирования на изменение конъюнктуры рынка;

- контроль, осуществляемый государственными органами, рекомендуется сфокусировать не на отчетах о добыче, а на финансовой отчетности, что поможет уменьшить сложность процедур представления отчетности и повысить гибкость производственных операций;

- в кодекс «О недрах и недропользовании» можно добавить информацию относительно стандартов отчетности системы CRIRSCO, участником которой является Казахстан. Это обеспечило бы эффективное внедрение стандартов CRIRSCO;

- рекомендуется содействовать наращиванию по- 
тенциала и развитию связей с системой высшего образования, тем самым повышая эффективность механизмов представления отчетности и осуществления контроля и надзора в отрасли;

6. внесение уточнений относительно геологической отчетности:

- в кодекс «О недрах и недропользовании» рекомендуется внести уточнения относительно функций Государственного фонда недр в области систематизации и обеспечения доступа к геологической информации;

- предлагается также добавить определение информации, признаваемой конфиденциальной, которая является исключением из положения о предоставлении открытого доступа к геологической информации;

7. расширение круга требований к экологической экспертизе и уточнение информации относительно водопользования:

- в кодекс «О недрах и недропользовании» рекомендуется внести требования относительно проведения оценки исходного состояния окружающей среды, помимо отбора проб воды;

- предлагается рассмотреть возможность включения в кодекс «О недрах и недропользовании» дополнительной информации для недропользователей, касающейся требований к водопользованию, и прямых отсылок к положениям национального водного законодательства;

8. усиление влияния поддержки, оказываемой недропользователями программам обучения кадров и НИОКР. Рекомендуется добавить более подробную информацию, касающуюся финансирования обучения казахстанских кадров и НИОКР из средств недропользователей, а также ужесточить меры по обеспечению прозрачности целевого использования таких средств, чтобы повысить результативность применения данного законодательного требования;

9. возможное продолжение реформ. Стабильность налогового режима значительно снижает потенциальные инвестиционные риски как для инвесторов, так и для государства. Это достигается либо путем включения положений о стабильности в налоговое законодательство, либо при помощи формирования соответствующего отношения к процессу разработки налогового законодательства и ожидаемым результатам в целом. Нестабильность налоговых условий является существенным риском, который усложняет предприятиям расчет норм прибыли и в конечном итоге сокращает потенциальные доходы государства.

Однако частое внесение изменений в Налоговый кодекс может подорвать доверие инвесторов, и, тем не менее, приходится принимать в расчет не только потребность в стабильности налоговой системы, но и готовность Казахстана продолжать работу над постепенным переходом на общепринятые международные стандарты. К тому же, уже имели место проблемы, возникающих со справочной информацией для налогоплательщиков (которую последние не всегда находят достаточной), и с расхождениями в толковании положений закона налоговыми органами. В отсутствии четкого понимания того, как именно должны применяться те или иные положения, риск возникновения разногласий между налогоплательщиками и властями возрастает.

Таким образом, можно сделать вывод, что одним из обязательных условий достижения устойчивого развития является наличие адекватных законов, нормативных актов и стандартов или горного законодательства, а также системы институциональных структур и комплекс мер, обеспечивающих выполнение этих условий.

\section{ЛИТЕРАТУРА}

1. Казахстанская фондовая биржа. Горно-металлургическая отрасль Республики Казахстан [Электрон. ресурс]. - 2019. - URL: https://kase.kz/files/ presentations/ru/KASE_mining_2019.PDF (дата обращения 15.10.2020).

2. Реформирование горной промышленности в Казахстане: инвестиции, устойчивое развитие, конкурентоспособность. Программа по повышению конкурентоспособности стран Евразии-2018 Организации экономического сотрудничества и развития [Электрон. ресурc]. - 2018.- URL: https://www. oecd.org/eurasia/countries/Kazakhstan_Mining_report_RUS.pdf (дата обращения 10.10.2020).

3. Кодекс Республики Казахстан «0 недрах и недропользовании» (с изменениями и дополнениями по состоянию на 30.12.2019 г.)

4. Кодекс Республики Казахстан «0 налогах и других обязательных платежах в бюджет (с изменениями и дополнениями по состоянию на 25.12 .2017 г.)

5. Каренов Р.С. Приоритеты стратегии индустриально-инновационного развития горнодобывающей промышленности Казахстана / Р.С. Каренов. - Астана: Изд-во КазУЭФМТ, 2010. - 539 с.

( ) Невматулина Карина Анваровна (carisha_07@mail.ru), Жидкоблинова Олеся Владимировна (olesya.zhidkoblinova@mail.ru), Мусатаева Асемгуль Амангазиевна (m_assem1984kz@mail.ru), Ставбуник Елена Анатольевна (sea826@yandex.kz). 